\title{
AVALIAÇÃO MACROSCÓPICA DA ATIVIDADE CICATRIZANTE DA PLANTA Luehea divaricata (Açoita-cavalo) NA TERAPÊUTICA TÓPICA DE FERIDAS CUTÂNEAS
}

(Macroscopic assessment of healing activity plan Luehea divaricata (flog-horse) in therapeutic topical skin wound)

\author{
Emanuelle Karine Frota Batista, Hebelys Ibiapina da Trindade, Flora Suzane \\ Parente Maia, Kelly Noilla de Sousa Araújo, Joao Macedo de Sousa, Maria do \\ Carmo de Souza Batista ${ }^{1}$ \\ ${ }^{1}$ Correspondência: mcbatista@ufpi.edu.br
}

RESUMO: O uso de fitoterápicos, com os mais diferentes objetivos, é feito desde tempos remotos. Dentre eles, a planta Luehea dicaricata (açoita-cavalo), tem sido proposta popularmente para fins diversos, incluindo a cicatrização de feridas. Porém, sua indicação popular, carece de investigações científicas mais aprofundadas. Com base nisto, este trabalho teve como objetivo avaliar a atividade cicatrizante de uma formulação a base de gel de quitosana acrescido ao extrato etanólico da casca do caule de L.divaricata nas concentrações de $2 \%$ e $4 \%$. Para tal foram produzidas feridas cirúrgicas no dorso de ratos Wistar, sendo utilizados 40 ratos machos divididos em cinco grupos. Para comparação de resultados utilizou-se para controle positivo, um gel comercial a base de ácidos graxos essenciais, vitaminas $A$ e $E$, óleos de copaíba e melaleuca e no grupo controle negativo, nada foi utilizado. Foi feito ainda um grupo em que se utilizou apenas a quitosana. Após 24 horas da cirurgia, iniciou-se o tratamento com aplicações duas vezes ao dia. A evolução da cicatrização foi avaliada diariamente e a mensuração da área das feridas feita a cada três dias. Os resultados da avaliação macroscópica foram submetidos à Análise de Variância e comparação de médias pelo Teste T ao nível de 5\% de significância. Formulações tópicas a base de gel de quitosana e extrato de $L$. divaricata a $4 \%$, aplicadas duas vezes ao dia, podem ser benéficas ao processo cicatricial do ponto de vista macroscópico, visto que podem otimizar a fase de fibroplasia da cicatrização. Além disso, a referida formulação induz menor exsudação, facilitando o processo cicatricial.

Palavras-chave: cicatrização; fitoterapia; quitosana; reparação tecidual

\begin{abstract}
The use of herbal medicines, with the most different purposes, is made since ancient times. Among them, the Luehea dicaricata plant (açoita-cavalo) has been proposed popularly for various purposes, including wound healing. However, its popular statement, needs more depth scientific research. On this basis, this study aimed to evaluate the healing activity of a formulation chitosan gel base added to ethanolic extract from the bark of L. divaricata stem in $2 \%$ and $4 \%$ concentrations. To this surgical wounds were made on the backs of rats being used 40 rats were divided into five groups. For comparison we used the results to a positive control, a commercial gel based on essential fatty acids, vitamins $A$ and $E$, copaiba oil and tea tree and the negative control group, nothing was used. It was also made a group in which chitosan is used only. After 24 hours of surgery began treatment with twice daily applications. The evolution of healing was evaluated daily and the measurement of the wound area cleaned every three days. The results of the macroscopic evaluation were submitted to ANOVA and means were compared by $T$ test at $5 \%$ significance level. Topical formulations chitosan gel base and $L$. divaricata extract $4 \%$, applied twice a day, can be beneficial to the healing process of the macroscopic point of view, as it can optimize fibroplasia phase of wound healing. Moreover, said formulation induces less exudation, facilitating the healing process.
\end{abstract}

Key Words: healing; phytotherapy; chitosan; tissue repair 


\section{INTRODUÇÃO}

A pele é o maior órgão do corpo e apresenta diversas funções como, manutenção da temperatura corporal, síntese de vitamina $\mathrm{D}$, proteção contra a ação de agentes externos (físicos, químicos e biológicos), atuação como órgão dos sentidos, proteção contra a perda excessiva de líquidos, entre outras. Uma descontinuidade no tecido epitelial prejudica as funções básicas de proteção da pele (SANTOS et al., 2011).

A cicatrização é um processo fisiológico que busca repor a continuidade dos tecidos. Esta pode ocorrer por primeira intenção, quando as bordas da ferida estão próximas e se unem imediatamente; segunda intenção, quando as bordas ficam separadas, sendo necessária a formação de tecido cicatricial, ocorrendo ainda em feridas contaminadas por microorganismos; e por terceira intenção, que procede do fechamento secundário de uma ferida, com utilização de sutura. É um processo caracterizado por três fases: inflamatória, proliferativa ou de fibroplasia e de maturação (SANTOS, 2010; SANTOS et al., 2011).

$\mathrm{Na}$ fase inflamatória há a liberação de substâncias vasoconstritoras, principalmente tromboxana A2 e prostaglandinas. Em seguida, ocorre a agregação plaquetária e ativação da via de coagulação. (NITZ et al., 2006; CAMPOS et al., 2007; SANTOS, 2010; SANTOS et al., 2011). A fase proliferativa é subdividida em quatro etapas: epitelização, angiogênese, formação de tecido de granulação e deposição de colágeno. A epitelização inicia após a lesão. A ferida é selada pela formação de coágulos e, em seguida, por migração de células epiteliais. Queratinócitos localizados na camada basal da epiderme residual, ou profundamente no epitélio, migram para a superfície da ferida. O TNF- $\alpha$ (fator de necrose tumoral alfa) estimula a angiogênese, que é caracterizada pela migração de células endoteliais e formação de capilares (CAMPOS et al., 2007).

O tecido de granulação é formado na área de lesão a partir do 4을 dia, e contém vários capilares neoformados, macrófagos, fibroblastos e matriz extracelular. Os fibroblastos dos tecidos vizinhos migram para a ferida. Em seguida 0 TGF- $\beta$ é liberado, estimulando os fibroblastos a produzirem colágeno tipo l e a transformarem-se em miofibroblastos, que promovem a contração da ferida (CAMPOS et al., 2007; SANTOS, 2010; SANTOS et al., 2011). A fase de maturação é caracterizada pela remodelação do colágeno, processo que se inicia ainda na formação do tecido de granulação e persiste por meses após a reepitelização. Nesta etapa, todos os processos ativados no início da lesão são gradativamente parados e a população celular, inclusive os fibroblastos, começa a sofrer apoptose, permanecendo apenas grande quantidade de colágeno, elementos da matriz e poucas células. As colagenases e outras proteínas produzidas por macrófagos e células epidérmicas dão direção correta às fibras colágenas difusas (SANTOS, 2010; CAETANO, 2012).

Conhecer a fisiopatologia da cicatrização e os fatores que podem acelerá-la ou retardá-la proporciona uma melhor avaliação e a escolha do tratamento mais adequado. Atualmente pesquisas têm avaliado também a sua importância na reabilitação funcional e estética do animal (VITORINO FILHO, 2011; BARRETO, 2011). Existem diferentes alternativas terapêuticas que permitem acelerar 0 processo de cicatrização de uma ferida. Independente da escolha, o método selecionado deve propiciar um ambiente favorável, permitindo progressão espontânea para não retardar o 
processo de reparação (PAGANELA et al., 2009).

Vários estudos referem o uso de plantas medicinais, ou seja, plantas que são capazes de aliviar ou curar enfermidades e têm tradição de uso como remédio em uma comunidade. As diversas propriedades e indicações terapêuticas de tais plantas têm permitido um avanço no seu uso, tanto na medicina humana como na veterinária. Muitas pesquisas são realizadas a fim de determinar a eficácia de produtos naturais que auxiliem no processo de reparo tecidual (PAGANELA et al., 2009; OLIVEIRA et al., 2010; ANVISA, 2014).

Dentre as plantas estudadas, pode-se citar a "açoita-cavalo", nome vulgar da Luehea divaricata Martius (Tiliaceae), espécie pertencente à ordem Malvales, subclasse Rosidae da classe Magnoliaceae. É encontrada em diferentes estados brasileiros como Bahia, Rio de Janeiro, Piauí, São Paulo, Minas Gerais, Goiás, Mato Grosso do Sul, Paraná, Santa Catarina, Rio Grande do Sul, Alagoas, Espírito Santo, além de outros países sul-americanos como: Argentina, Paraguai e Uruguai. As folhas de L. divaricata são usadas e comercializadas popularmente para 0 tratamento de disenteria, leucorréia, reumatismo, blenorragia e tumores, as flores para bronquite e as raízes com finalidades depurativas (TANAKA et al., 2005; MÜLLER, 2006; CARVALHO, 2008; WALKER et al., 2008). Já as cascas são utilizadas para acelerar a cicatrização, tratamento de acne, inflamações e em afecções do trato geniturinário (SIQUEIRA, 2006).

A quitosana, por sua vez, também vem ganhando cada vez mais espaço como recurso terapêutico popular no processo de cicatrização. Trata-se do derivado mais estudado da quitina, substância que se encontra em abundância no exoesqueleto de insetos e crustáceos, além de estar presente em algas, moluscos e na parede celular de fungos (KURITA, 2006; AZEVEDO et al., 2007).

Silva e colaboradores (2006) relataram várias propriedades biológicas da quitina e quitosana, entre elas: atividade antimicrobiana, efeito coagulante, aceleração da cicatrização, efeito analgésico, tratamento de osteoartrite, redução de peso, entre outros. Como curativo, pode-se citar seu potencial de acelerar o processo de cicatrização ao ativar macrófagos funcionais.

De acordo com estes diferentes estudos, verifica-se que a quitosana torna-se potencialmente viável à aplicação na cicatrização de feridas de pele, assim como a planta açoita-cavalo, muito indicada popularmente para este fim. Considerando a facilidade de obtenção da L. divaricata em nossa região e os poucos estudos abordando as propriedades terapêuticas desta planta, bem como a carência de trabalhos científicos abordando o efeito cicatrizante da quitosana, este trabalho teve como objetivo avaliar a atividade cicatrizante do extrato etanólico da casca do caule de $L$. divaricata acrescido de gel de quitosana, usado topicamente, em duas diferentes concentrações.

\section{MATERIAL E MÉTODOS}

\section{Local do experimento}

A pesquisa foi realizada no Laboratório de Ciências Fisiológicas do Departamento de Morfofisiologia Veterinária do Centro de Ciências Agrárias da Universidade Federal do Piauí (CCA/UFPI).

\section{Animais}

Foram utilizados 40 ratos Wistar, machos de 2-4 meses, mantidos em ambiente com temperatura controlada 
$\left(23 \pm 2^{\circ} \mathrm{C}\right)$ e ciclo claro/escuro de 12 horas com água e alimento ad libitum. Os animais foram fornecidos pelo Biotério do Centro de Ciências Agrárias da Universidade Federal do Piauí. Foram feitos cinco grupos com oito animais cada. Ao fim do experimento os animais foram eutanasiados com sobredose de tiopental sódico $(50 \mathrm{mg} / \mathrm{kg})$. As normas recomendadas pelo International Guiding Principles for Biomedical Research Involving Animals de Geneva (1985) e pelo Conselho Federal de Medicina Veterinária (Resolução no 1000 de 11 de Maio de 2012) foram obedecidas.

O protocolo experimental desta pesquisa foi aprovado pelo Comitê de Ética em Experimentação com Animais da Universidade Federal do Piauí sob o no 0106/12.

Coleta e obtenção do extrato de L. divaricata

As cascas do caule de $L$. divaricata foram coletadas no Povoado Alegria, zona rural de Teresina (PI). A identificação da planta foi feita no Herbário Graziela Barroso do Centro de Ciências da Natureza da Universidade Federal do Piauí (CCN/UFPI), sob o número de registro 30.119 .

A produção do extrato etanólico se deu a partir das cascas do caule de L. divaricata. A matéria prima foi seca em estufa a $40 \pm 1{ }^{\circ} \mathrm{C}$, trituradas em moinho elétrico e acondicionadas em frascos estéreis. As cascas pulverizadas foram submetidas ao processo de maceração com etanol a $99 \%$ por três extrações sucessivas. Posteriormente o concentrado foi processado em rotavapor a $50^{\circ} \mathrm{C}$, sendo então acondicionado em frasco de vidro (SUMITRA et al., 2005; PONRASU e SUGUNA, 2012).

Para preparo da pomada, o gel de quitosana foi incorporado ao extrato etanólico liofilizado da L. divaricata nas concentrações de $2 \%$ e $4 \%$. Tal formulação foi manipulada pelo Núcleo de Tecnologia Farmacêutica do Centro de Ciências da Saúde (NTF/CCS UFPI).

\section{Atividade cicatrizante}

Foi feita a avaliação macroscópica do processo cicatricial por segunda intenção. Para tal foram produzidas feridas pelo método cirúrgico, utilizando-se anestesia dissociativa com cetamina e xilazina, na posologia de $50 \mathrm{mg} / \mathrm{kg}$ e $8 \mathrm{mg} / \mathrm{kg}$, respectivamente, associadas na mesma seringa e aplicadas por via intraperitoneal. Após a anestesia, foram realizadas a tricotomia e a antissepsia com álcool iodado a $2 \%$, sendo feita então a demarcação da área da pele pela aderência de esparadrapo na dimensão de $1,0 \mathrm{~cm} 2$, seguida de exérese do retalho da pele, conforme técnica descrita por Nascimento e Batista (1998) e Barreto (2011).

Foram formados cinco grupos com oito ratos Wistar cada, conforme 0 delineamento experimental constante no Quadro 1.

Quadro 1 - Delineam ento experimental para avaliação do tratamento tópico de lesões cutâneas em ratos Wistar com formulações a base de gel de quitosana associado a extrato de $L$. divaricata. Teresina, 2014

\begin{tabular}{|c|c|c|c|}
\hline Grupos & $\begin{array}{c}\begin{array}{c}\text { Número } \\
\text { de } \\
\text { animais }\end{array} \\
\end{array}$ & Tratamento & $\begin{array}{c}\text { Esquema de } \\
\text { administração }\end{array}$ \\
\hline $\begin{array}{l}\text { Controle negativo (CN) } \\
\text { Controle positivo (CP) }\end{array}$ & 8 & $\begin{array}{c}\text { Cicatrização espontânea } \\
\text { Gel comercial a base de ácidos graxos } \\
\text { essenciais (AGE), vitaminas } \mathrm{A} \text { e E } \\
\text { óleos de copaiba e melalenca* }\end{array}$ & $\begin{array}{l}\text { Tópico, duas vezes ao } \\
\mathrm{dia}\end{array}$ \\
\hline Extrato a $2 \%$ & 8 & $\begin{array}{l}\text { Gel de quitosana }+ \text { Extrato de } L . \\
\text { divaricata } \mathrm{a} 2 \%\end{array}$ & $\begin{array}{l}\text { Tópico, duas vezes ao } \\
\text { dia }\end{array}$ \\
\hline $\begin{array}{c}\text { Extrato a } 4 \% \\
\text { Quitosana }\end{array}$ & $\begin{array}{l}8 \\
8\end{array}$ & $\begin{array}{l}\text { Gel de quitosana + Extrato de } L . \\
\text { divaricata a } 4 \% \\
\text { Gel de quitosana }\end{array}$ & $\begin{array}{c}\text { Tópico, duas vezes ao } \\
\text { dia } \\
\text { Tópico, duas vezes ao } \\
\text { dia }\end{array}$ \\
\hline
\end{tabular}

A avaliação macroscópica constou de observações clínicas do processo cicatricial e análise de contração das feridas. A avaliação clínica foi feita pela observação diária das feridas, nas quais foram avaliados os seguintes parâmetros: exsudato, hiperemia, presença de pus e formação de crosta (OLIVEIRA et al., 2010; VITORINO FILHO, 2011). 
A área das feridas foi mensurada com 0 auxílio de paquímetro, nos dias 1, 4, 7, 10 e 13 de pós-operatório e para calculá-la utilizou-se a seguinte fórmula: $A=$ п. R. $r$, onde " $A$ " representa a área $\left(\mathrm{cm}^{2}\right)$; " $\mathrm{R}$ ", o raio maior e "r", o raio menor (PRATA et al., 1988). Foi feito o cálculo do percentual de contração da área das feridas por meio da seguinte fórmula: (área inicial - área do dia da medida) / área inicial x $100=$ percentual de contração no dia da medida (AGREN et al., 1997).

\section{$\underline{\text { Análise estatística }}$}

Os resultados das áreas das feridas experimentais e dos percentuais de contração foram analisados estatisticamente por meio da análise de variância (ANOVA) e comparação de médias pelo Teste $T$ de Student, adotando-se um nível de significância de $5 \%$.

\section{RESULTADOS E DISCUSSÃO}

Todas as lesões apresentaram cicatrização por segunda intenção, ocorrendo a substituição do tecido lesionado por outro semelhante (ZANINI, 1990; SHETTY e BERTOLAMI, 1992), caracterizado pela formação de tecido de granulação e contração da ferida (COELHO, 1998).

$\mathrm{Na}$ maioria dos grupos o exsudato estava ausente ou presente de forma discreta, com exceção do grupo quitosana, com lesões que apresentavam presença de moderada a intensa de exsudato até $07^{\circ}$ dia. Os sinais de exsudação foram menos freqüentes no grupo tratado com 0 extrato a $4 \%$ e no grupo controle negativo, comparativamente aos demais grupos. O exsudato, quando presente, mostrava-se de aspecto seroso, característico de feridas não contaminadas. Resultados semelhantes foram encontrados por Vitorino Filho (2011). A partir do 9 dia, o exsudato estava ausente em todos os grupos.

Em feridas agudas, a presença de exsudato é normal durante as primeiras 48 a 72 horas. Depois de tal período, a exsudação é sinal de prejuízo à cicatrização (BATES- JENSEN, 1998). Quando o exsudato persiste, há uma desagregação da crosta favorecendo o desenvolvimento de microorganismos entre ela e o tecido de granulação (OLIVEIRA, 1992). Desta forma, animais do grupo quitosana apresentaram uma cicatrização mais lenta, pois nestes, o exsudato persistiu até $07^{\circ}$ dia de tratamento. Estes resultados não corroboram com o estudo de Helou et al. (2008), em que se verificou uma progressiva evolução da cicatrização e redução gradativa do exsudato com 0 uso de um composto a base de quitosana a $5 \%$ em feridas de bovinos.

A hiperemia também estava presente em todos os grupos. Animais dos grupos extrato a $2 \%$, extrato a $4 \%$ e quitosana mostraram uma intensa hiperemia, especialmente nos três primeiros dias. A hiperemia foi se tornando branda nos grupos extrato a $2 \%$ e extrato a $4 \%$ até o $6^{\circ}$ dia. Do $7^{\circ}$ ao 9o dia, os animais desses grupos apresentavam hiperemia moderada, tornando-se então, ausente ou discreta nos dias seguintes. Já no grupo quitosana, a hiperemia permaneceu de moderada a intensa até o $8^{\circ}$ dia. Tal parâmetro durou mais no grupo controle negativo, com presença de hiperemia intensa até o $11^{\circ}$ dia.

A hiperemia caracteriza-se por ser um fenômeno vascular envolvida no processo de inflamação durante 0 reparo tecidual, tendo início alguns minutos após a ação traumática, tempo este em que se processa a liberação de mediadores químicos, principalmente a histamina (GUYTON, 1998). Nos resultados obtidos nesta pesquisa, a hiperemia foi visualizada em todos os 
grupos, variando apenas em sua intensidade, indicando que não houve ação significativa dos tratamentos a $2 \%$ ou a $4 \%$ no que se refere ao controle da reação inflamatória. Houve uma diminuição progressiva da intensidade da hiperemia com o tempo, com exceção do grupo controle negativo.

O parâmetro pus manteve-se uniforme. Estava ausente em todos os grupos ao longo dos dias na grande maioria dos animais. O pus geralmente está associado a um processo de infecção bacteriana. Deste modo, o estudo comprovou que todos os cuidados necessários para a correta antissepsia dos animais e assepsia das gaiolas, foram rigorosamente obedecidos ao longo do experimento.

Quanto à formação de crosta, observou-se que estava ausente durante as primeiras 48 horas no grupo quitosana. A partir do $3^{\circ}$ dia houve formação de crosta em todos os grupos. Do $3^{\circ}$ ao $7^{\circ}$ dia verificou-se a sua presença em quase $100 \%$ dos animais dos grupos controle negativo, controle positivo, extrato a $2 \%$ e a $4 \%$. Do $12^{\circ}$ dia em diante, observou-se redução de tamanho da crosta, de coloração avermelhada, na quase totalidade dos animais do grupo extrato a $2 \%$, extrato a $4 \%$ e controle positivo. Resultados semelhantes foram encontrados por Oliveira et al. (2010), em seu grupo controle também foi verificada uma redução de tamanho da crosta a partir do $12^{\circ}$ dia, no tratamento de feridas cutâneas de caprinos com jucá (Caesalpinia ferrea).

Para Martin (1997) a crosta é formada logo nas fases iniciais da cicatrização sendo composta por fibrina, agregação plaquetária, embebidas em células sanguíneas. Tal mecanismo protege a ferida contra a perda de eletrólitos e fluidos e contra a contaminação por agentes nocivos (MONACO e LAWRENCE, 2003). Já para Andrade (2006), a presença de crosta em uma ferida não é considerada pré-requisito para a cicatrização, podendo apresentar vantagens e desvantagens para a evolução do processo cicatricial. Como desvantagem está a formação de crosta com um aspecto seco, podendo ainda retardar a contração da pele durante a cicatrização.

$\mathrm{Na}$ análise de contração das feridas, verificou-se que, em todos os grupos, houve uma diminuição progressiva das áreas das lesões ao longo dos dias. Nenhuma ferida apresentou área maior que a inicial nos dias $4,7,10$ e 13 de pós-operatório $A$ contração das feridas é mediada por citocinas e em particular pelo Fator de Crescimento Transformador (TGF). A diminuição da área cruenta ocorreu por conta do mecanismo de contração e do movimento centrípeto dos limites da ferida em direção ao centro, com o objetivo de diminuir a área a ser recoberta pelo epitélio em proliferação, caracterizando a cicatrização por segunda intenção (PEACOCK e COHEN, 1990; MADDEN e AREM, 1991).

Ao 4ำ dia de observação, verificou-se que houve diferença estatisticamente significativa entre os grupos controle negativo e quitosana e os demais grupos, com áreas de 0,80 $\mathrm{cm}^{2}$ e $0,71 \mathrm{~cm}^{2}$, respectivamente. Observou-se ainda que o percentual de contração foi muito maior no grupo controle negativo com média de $50,6 \%$, do que no grupo quitosana com uma média de $31,7 \%$ de contração.

Do $7^{\circ}$ dia de observação em diante não houve diferença significativa entre os grupos, porém ao $7^{\circ}$ dia verificou-se que a menor área de ferida foi encontrada no grupo extrato a $4 \%$, com uma média de $0,28 \mathrm{~cm}^{2}$. Já no grupo controle negativo a média da área foi de $0,59 \mathrm{~cm}^{2}$. Os percentuais de contração nos grupos extrato a $4 \%$ e controle

foram, 
respectivamente, 68,5\% e 26,2\%. Estes resultados diferem dos encontrados por Oliveira et al. (2010) que verificou ao $7^{0}$ dia de tratamento, um maior percentual de contração no grupo controle $(28,85 \%)$, contra apenas $7,51 \%$ no seu grupo tratado.

No $10^{\circ}$ dia, as menores áreas das feridas foram observadas nos grupos: extrato a $4 \%$ e controle positivo, respectivamente, $0,07 \mathrm{~cm}^{2}$ e $0,08 \mathrm{~cm}^{2}$. No último dia de observação, o grupo controle positivo estava quase completamente

cicatrizado, apresentando um percentual de contração de $97,5 \%$, enquanto que os grupos extrato a $2 \%$ e extrato a $4 \%$ apresentaram percentuais de contração de $85,7 \%$ e $71,4 \%$, respectivamente.

As médias das áreas cirúrgicas das feridas experimentais e os percentuais de contração estão representados na tabela 1 e na figura 9 , respectivamente.

Tabela 1 - Média da área cirúrgica das feridas experimentais (em centímetros quadrados), confeccionadas em ratos e tratadas com formulacões tópicas à base de Luehea divaricata segundo as mensuraç̃es procedidas nos dias 1, 4, 7,10,13 após o início do tratamento

\begin{tabular}{|c|c|c|c|c|c|}
\hline Tratamento & $\begin{array}{c}\begin{array}{c}\text { Média da } \\
\text { área } \\
\text { Dia 1 }\end{array} \\
\end{array}$ & $\begin{array}{c}\begin{array}{c}\text { Média da } \\
\text { área } \\
\text { Dia } 4\end{array} \\
\end{array}$ & $\begin{array}{c}\text { Média da } \\
\text { área } \\
\text { Dia } 7 \\
\end{array}$ & $\begin{array}{c}\text { Média da } \\
\text { área } \\
\text { Dia 10 } \\
\end{array}$ & $\begin{array}{c}\text { Média da } \\
\text { área } \\
\text { Dia 13 } \\
\end{array}$ \\
\hline C. negativo & $1,62 \mathrm{a}$ & $0,80 \mathrm{~b}$ & $0,59 \mathrm{a}$ & $0,11 \mathrm{a}$ & $0,01 \mathrm{a}$ \\
\hline C. positivo & $1,43 \mathrm{ab}$ & $1,10 \mathrm{a}$ & $0,62 \mathrm{a}$ & $0,08 \mathrm{a}$ & $0,002 a$ \\
\hline Extrato $2 \%$ & $1,02 \mathrm{c}$ & $0,88 \mathrm{ab}$ & $0,42 \mathrm{a}$ & $0,14 \mathrm{a}$ & $0,02 \mathrm{a}$ \\
\hline Extrato $4 \%$ & $1,27 \mathrm{bc}$ & $0,89 \mathrm{ab}$ & $0,28 \mathrm{a}$ & $0,07 \mathrm{a}$ & $0,02 \mathrm{a}$ \\
\hline Quitosana & $1,04 \mathrm{c}$ & $0,71 \mathrm{~b}$ & $0,31 \mathrm{a}$ & $0,18 \mathrm{a}$ & $0,10 \mathrm{a}$ \\
\hline
\end{tabular}

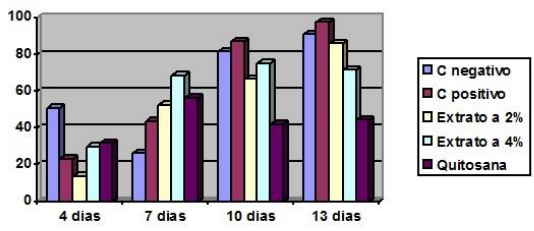

Figura 1 - Contração de feridas experimentais confeccionadas em ratos (ex pressa em porcentagem), tratadas com formulações tópicas à base de Luehea divaricata, segundo as mensuraç̃oes procedidas nos dias $4,7,10,13$ após o início do tratam ento.

O estudo em questão baseou-se na avaliação macroscópica, que embora muitas vezes subjetiva, mostra-se de grande importância para o acompanhamento do reparo cutâneo. Na prática corrente, é o meio disponível mais usual, de baixo custo e que gera excelentes informações em relação ao comportamento dos eventos biológicos durante a reparação do tecido epitelial (SANTOS, 2010).

O uso popular da planta $L$. divaricata como cicatrizante influenciou o presente estudo. Conforme afirmou Elisabetsky (2003), a indicação terapêutica popular de uma espécie vegetal serve como atalho para pesquisas mais aprofundadas. O seu uso tradicional pode ser encarado como uma pré-triagem quanto à propriedade terapêutica. Do mesmo modo, Siqueira (2006), influenciado pela indicação popular, verificou a eficácia de $L$. divaricata no tratamento de úlceras gástricas em ratos através da utilização do extrato hidroalcoólico de sua casca, e observou a redução do índice de lesões ulcerativas produzidas por indometacina e etanol.

A triagem fitoquímica desse extrato relevou a presença de flavonóides, taninos, antocianinas e triterpenos. Tais substâncias apresentam diferentes efeitos farmacológicos, dentre elas, os compostos flavonoídicos são descritos como potencialmente cicatrizantes (SIMÕES et al., 2004).

Vários autores já estudaram o uso tópico de fitoterápicos com o objetivo de influenciar 0 processo cicatricial, obtendo diferentes resultados. Batista et al. (2014), estudando a ação de formulações tópicas à base de látex de aveloz (Euphorbia tirucalli) na cicatrização de feridas, concluíram que as soluções aquosas do látex da referida planta, nas concentrações de $6,25 \%$ e $3,12 \%$ podem ser usadas na cicatrização de feridas, pois induzem menor hiperemia e exsudação. Vitorino Filho (2011), em sua pesquisa a cerca do uso de polissacarídeo extraído do exsudato de cajueiro (Anacardium occidentale) no reparo tecidual, verificou que 0 tratamento tópico com a solução na concentração de $1,5 \%$, duas vezes ao dia, diminui a fase flogística e intensifica 
a reepitelização na fase inicial do processo cicatricial.

$\mathrm{O}$ agente comercial (gel à base de $A G E$, vitaminas $A$ e $E$, óleos de copaíba e melaleuca), classicamente empregado na cicatrização de feridas cutâneas, não se mostrou diferente em relação aos demais grupos quanto à redução do tempo final de cicatrização de feridas cutâneas do dorso de ratos. Ao longo dos dias, entretanto, pode-se observar uma melhora nos percentuais de contração das feridas no grupo controle positivo, indicando que seu efeito cicatrizante passa a ser melhor com o tempo, no estudo em questão, a partir do $10^{\circ}$ dia, superando os demais grupos a partir de então. Os percentuais de contração das feridas foram maiores a partir do $7^{\circ}$ dia. Para vários autores tal fato se justifica, pois entre $07^{\circ}$ e $014^{\circ}$ dia ocorre a fase de fibroplasia da cicatrização, com presença de fibroblastos e miofibroblastos. Oliveira et al. (2010) também encontrou maiores percentuais de contração a partir do $7^{0}$ dia.

No presente trabalho, embora não tenha havido diferenças significativas entre grupos quanto as médias das áreas cirúrgicas das feridas experimentais, as formulações com o extrato de $L$. divaricata a $4 \%$ apresentaram uma menor área de ferida no $7^{\circ}$ e no $10^{\circ}$ dia de tratamento, indicando que a formulação pode apresentar resultados benéficos ao processo cicatricial por otimizar a fase de fibroplasia da cicatrização. Do mesmo modo, na análise clínica foi constatado que no grupo extrato a $4 \%$, os sinais de exsudação foram menos frequentes, favorecendo o processo de reparo tecidual. Resultados diferentes foram encontrados por Vitorino Filho (2011), o qual verificou uma otimização do período inflamatório e da reepitelização tissular do processo cicatricial pela utilização do polissacarídeo extraído do exsudato de cajueiro na concentração de 1,5\%. Barreto (2011) por sua vez, verificou um processo cicatricial esteticamente mais organizado, com menos sinais de hiperemia e exsudação com a utilização de formulações a base de Aloe vera a $20 \%$.

O grupo quitosana mostrou melhores resultados ao $4^{\circ}$ dia de observação, apresentando a menor área de ferida $\left(0,71 \quad \mathrm{~cm}^{2}\right) \quad(P<0,05)$. Entretanto, pela análise clínica, foi um dos grupos com maior incidência de hiperemia e presença de exsudato, características que quando intensamente presentes, podem prejudicar a reparação tissular.

Comparativamente ao grupo extrato a $4 \%$, o tratamento a $2 \%$ foi inferior, visto que seu desempenho nos percentuais de contração das feridas só foi superior ao tratamento a $4 \%$ no último dia de observação.

\section{CONCLUSÃO}

As formulações tópicas à base do extrato de L. divaricata nas concentrações de $2 \%$ e $4 \%$, associadas à quitosana, bem como a quitosana isolada, podem ser alternativamente empregadas na cicatrização de feridas, visto que não mostraram diferenças significativas do gel comercial, classicamente empregado no reparo cutâneo, quanto ao tempo final de cicatrização. Em comparação com a quitosana isolada, os tratamentos com o extrato de L. divaricata a $2 \%$ e a $4 \%$ à ela associados, mostram-se superiores e, comparativamente entre si, o tratamento a $4 \%$ é mais efetivo, visto que desencadeia uma cicatrização esteticamente mais organizada. 


\section{NOTAS INFORMATIVAS}

The research was approved by the Ethical Committee of the Federal University of Rio Grande do Sul (Project ํo 9934).

\section{REFERÊNCIAS}

AGREN, M. S.; MERTZ, P. M.; FRANZÉN, L. A comparative study of three occlusive dressing in the treatment of full-thickness wounds in pigs. Journal of the American Academy Dermatology, v.36, n.1, p.53-8, 1997.

ANDRADE, L. S. S. Avaliação terapêutica das pomadas do polissacarídeo do Anacardium occidentale L. e do extrato em pó da Jacaratia corumbensis $\mathrm{O}$. Kuntze em feridas cutâneas produzidas experimentalmente em caprinos (Capra hircus L.) Aspectos clinicos, bacteriológicos e histopatologicos, 2006. 76f. Tese (Doutorado em Ciência Veterinária) Departamento de Medicina Veterinária, Universidade Federal de Rural de Pernambuco, Recife.

ANVISA - Agência Nacional de Vigilância Sanitária. Fitoterápicos. Gerência de Medicamentos Isentos, Específicos, Fitoterápicos e Homeopáticos - GMEFH. 2014. Disponível em

http://www.anvisa.gov.br/medicamentos/fitoterap icos/poster_fitoterapicos.pdf> Acesso em: 05 set. 2014

AZEVEDO, V. V. C.; CHAVES, S. A.; BEZERRA, D. C.; LIA FOOK, M. V.; COSTA, A. C. F. M. Quitina e Quitosana: aplicações como biomateriais. Revista Eletrônica de Materiais e Processos, v.2, n.3, p.27-34, 2007.

BARRETO, F. M. Uso do gel mucilaginoso das folhas de Aloe vera L. na terapêutica de feridas cutâneas aspectos clínicos e histológicos. Teresina, 2011. 115f. Tese de doutorado, Programa de Pós-Graduação em Ciência Animal, Universidade Federal do Piauí, Teresina-PI.

BATES - JENSEN, B. M. Management of exsudate and infection. In: SUSSMAN, C; BATES-JENSEN, B.M., Ed. Wound care: a collaborative practice manual for physical therapists and nurses. Gaithersburg: Aspen Publishers; 1998. p.159-77.

BATISTA, E. K. F.; COSTA, K. K. S.; SÁ, E. Avaliação do efeito de formulações com o látex da Euphorbia tirucalli na terapêutica tópica de feridas cutâneas: aspectos clínicos e histopatológicos. Medicina Veterinária, Recife, v. 8, n. 2, p.1-11, 2014.

CAETANO, G. F. Biomembrana de quitosanaalginato na cicatrização de úlceras cutâneas em ratos. São Paulo, 2012. 88p. Dissertação (Mestrado em Biotecnologia) - Instituto Butantan - Universidade de São Paulo, São Paulo.

CAMPOS, A. C. L.; BORGES-BRANCO, A.; GROTH, A. K. Cicatrização de Feridas. Arquivos Brasileiros de Cirurgia Digestiva, Curitiba - PR, v. 20, n. 1, p.51-58, 2007.

CARVALHO, P. E. R. Açoita-Cavalo (Luehea divaricata). Circular Técnica 147. Embrapa Florestas. Colombo - PR. 2008. Disponível em

http://www.cnpf.embrapa.br/publica/circtec/edico es/circ-tec147.pdf> Acesso em: 06 set. 2014.

COELHO, M. C. O. C. Substitutos temporários de pele no processo cicatricial de falhas cutâneas: estudo experimental em cães (Canis familiaris), 1998. 102f. Tese (Doutorado em Ciência Animal) - Escola de Veterinária, Universidade Federal de Minas Gerais, Belo Horizonte.

ELISABETSKY, E. Etnofarmacologia. Ciência e Cultura, São Paulo, v.55, n.3, p. 35-36, 2003.

GUYTON, A. C. Tratado de fisiologia médica. 8a. ed. Rio de Janeiro: Guanabara Koogan, 1998. 864p.

HELOU, J. B.; CORRÊA, F. A. F.; REZENDE, P. $M$ et al. Descorna plástica em bovinos: uso tópico de um composto a base de quitosana a $5 \%$ como auxiliar na cicatrização de feridas contaminadas (resultados preliminares). Anais. Congresso Brasileiro de Veterinária Conbravet, 2008.

KURITA, K. Chitin and Chitosan: functional biopolymers from marine crustaceans. Marine Biotechnology, Cambridge, v.8, n.3, p.203-226, 2006.

MADDEN, J.; AREM, A. A cicatrização das feridas. Aspectos biológicos e clínicos. In:

SABISTON, D. Tratado de cirurgia. 14. ed. Rio de Janeiro: Guanabara Koogan, 1991. p. 156168.

MARTIN, P. Wound Healing - Aiming for Perfect Skin Regeneration, Science, v. 276, p. 78-80, 1997.

MONACO, J. L.; LAWRENCE, W. T. Acute Wound healing - Na overvien. Clinics in Plastic Surgery, v.3, p.1-12, 2003.

MÜLLER, J. B. Avaliação das atividades antimicrobiana, antioxidante e antinociceptiva 
das folhas da Luehea divaricata Martius. 2006. 99 p. Dissertação (Mestrado em Ciências Farmacêuticas). Universidade Federal de Santa Maria, Santa Maria - RS.

NASCIMENTO, M. J. L.; BATISTA, M. C. S. Avaliação macro e microscópica do processo cicatricial de feridas experimentais de camundongos tratadas topicamente com açúcar. In: Seminário de Iniciação Científica da UFPI, 6. 1998, Teresina. Anais...Teresina: Universidade Federal do Piauí, 1998.

NITZ, A. C.; ELY, J. B.; D'ACAMPORA, A. J. et al. Estudo morfométrico no processo de cicatrização de feridas cutâneas em ratos, usando: Coronopu didymus e Calendula officinali. Arquivos Catarinenses de Medicina, Santa Catarina, v. 35, n. 4, p.74-79, 2006.

OLIVEIRA, A. F.; BATISTA, J.S.; PAIVA, E.S. et al. Avaliação da atividade cicatrizante do jucá (Caesalpinia ferrea Mart. ex Tul. var. ferrea) em lesões cutâneas de caprinos. Revista Brasileira de Plantas Medicinais, Botucatu, v.12, n.3, p.302-310, 2010.

OLIVEIRA, H. P. Traumatismos nos animais domésticos. Cadernos Técnicos da Escola de Veterinária, UFMG, v.1, n.7, p.1-57. 1992.

PAGANELA, J. C.; RIBAS, L. M.; SANTOS, C. A. et al. Abordagem clínica de feridas cutâneas em eqüinos. Revista Portuguesa de Ciências Veterinárias, Pelotas - RS, v. 104, p. 569-572, 2009.

PEACOCK, E. E.; COHEN, I. K. Wound healing. In: McCARTHY, J. G.; MAY JR., J. W.; LITTLER, J. W. Plastic surgery. Philadelphia: WB Saunders, v. 1, 1990. p. 167.

PONRASU, T.; SUGUNA, L. Efficacy of Annona squamosa on wound healing in streptozotocininduced diabetic rats. International Wound Journal, 2012, DOI: 10.1111/j.1742481X.2011.00924.X

PRATA, M. et al. Uso tópico do açúcar em feridas cutâneas, estudo experimental em

ratos. Acta Cirúrgica Brasileira, v.3, n.2, p.43-8, 1988.

SANTOS, J. B.; PORTO, S. G.; SUZUKY, L. M. et al. Avaliação e tratamento de feridas. 2011. Disponível em: http://www.lume.ufrgs.br/bitstream/handle/10183 /34755/000790228. pdf?sequence $=1>$. Acesso em: 05 set. 2014.

SANTOS, S. D. Estudo histológico da cicatrização cutânea em ratos após o uso da luz laser 780nm. João Pessoa: Universidade Federal da Paraíba, 2010. Trabalho monográfico - Universidade Federal da Paraíba, 2010.
SHETTY, V.; BERTOLAMI, C. The physiology of wound healing. In: PETERSON, et al. Oral and Maxilar Surgery. Philadelphia: Lippincot Company, cap. 1, p.3 - 18, 1992.

SILVA, H. S. R. C.; SANTOS, K. S. C. R. dos; FERREIRA, E. I. Quitosana: derivados hidrossolúveis, aplicações farmacêuticas e avanços. Química Nova, São Paulo, v.29, n.04, p.776 - 785, 2006.

SIMÕES, C. M. O.; SCHENKEL, E. P.; GOSMANN, G. et al. Farmacognosia; da planta ao medicamento. Porto Alegre - Florianópolis: UFRGS/ UFSC, 2004.

SIQUEIRA, M. G. Atividade antiulcerogênica do extrato bruto hidroalcoólico da Luehea divaricata Martus et Zuccarine. Campinas, 2006. 89 p. Dissertação de mestrado, Programa de PósGraduação de Ciências Médicas. Universidade Estadual de Campinas, Campinas-SP.

SUMITRA, M. MANIKANDAN, P.; SUGUNA, L. Efficacy of Butea monosperma on dermal wound healing in rats. The International Journal of Biochemistry and Cell Biology, v.37, p.566-573, 2005.

TANAKA, J. C. A. et al. Constituintes Químicos de Luehea divaricata Mart. (Tiliaceae). Química Nova, v. 28, n. 5, p. 834-837, 2005.

VITORINO FILHO, R. N. L. Uso de polissacarídeo extraído da casca de cajueiro (Anacardium occidentale L.) na terapêutica tópica de feridas. Teresina, 2011. 65p. Dissertação (Mestrado em Ciência Animal) Universidade Federal do Piauí, Teresina-PI.

WALKER, C. I. B.; ZANETTI, G. D.; CERON, C. $\mathrm{S}$. et al. Morfoanatomia e Histoquímica das Folhas de Luehea divaricata Mart. Latin American Journal of Pharmacy, v.27, n.2, p.203210, 2008.

ZANINI, S. A. Cirurgia e traumatologia buçomaxilo-facial. Rio de Janeiro: Revinter. cap.1, p.1-6, 1990. 